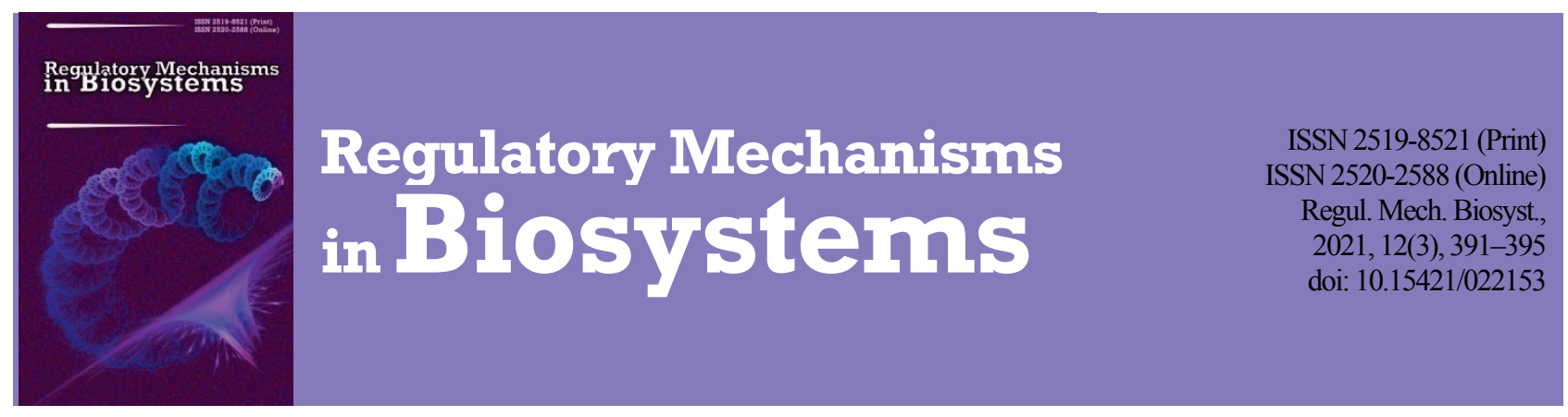

\title{
The effect of nanosilver in carriers based on polymer/inorganic hybrids on the quality and safety of edible chicken eggs
}

\author{
L. V. Shevchenko*, Y. Y. Dovbnia*, T. B. Zheltonozhskaya**, N. M. Permyakova**, L. M. Vygovska*, V. O. Ushkalov* \\ *National University of Life and Environmental Sciences of Ukraine, Kyiv, Ukraine \\ **Institute of Macromolecular Chemistry, NAS of Ukraine, Kyiv, Ukraine
}

Article info

Received 24.07.2021

Received in revised form 20.08.2021

Accepted 21.08.2021

National University of Life and Environmental Sciences of Ukraine, Heroïv Oborony st., 15, Kyiv, 03041, Ukraine. Tel.: +38-050-193-10-29. E-mail:

shevchenko_laris@ukr.net

Institute of Macromolecular Chemistry, NAS of Ukraine Kharkivske Shosse, 48, Kyiv, 02160, Ukraine. Tel.: $+38-050-782-55-40$ E-mail:

zheltonozhskaya@ukr.net

\begin{abstract}
Shevchenko, L. V., Dovbnia, Y. Y., Zheltonozhskaya, T. B., Permyakova, N. M., Vygovska, L. M., \& Ushkalov, V. O. (2021). The effect of nanosilver in carriers based on polymer/inorganic hybrids on the quality and safety of edible chicken eggs. Regulatory Mechanisms in Biosystems, 12(3), 391-395. doi:10.15421/022153

One of the modern antibacterial agents that are an alternative to antibiotics are nanoparticles of noble metals, including silver. To reduce their toxicity, cumulative effect and prolong the effect in animals, there is ongoing work on development and improvement of the methods for their synthesis using various carriers, including those based on polymer/inorganic hybrids. In this study, the quality and safety of edible eggs were determined on Hy-Line laying hens using W36 solutions of nanosilver in carriers based on polymer/inorganic hybrids (AgNPs/SPH) in the concentration of $0.0,1.0$ and $2.0 \mathrm{mg} / \mathrm{L}$ of water $(0.0,0.2$ and $0.4 \mathrm{mg}$ per hen per day) three times with 10 day interval. We determined that one-, two- and three-time feeding of nanosilver in doses of 0.0, 0.2 and $0.4 \mathrm{mg}$ per hen per day did not affect water consumption, feed, egg productivity, as well as dry matter content, crude protein, fat, ash, and calcium and phosphorus in eggs for 30 days. Contamination of the surface of the shell and yolks of eggs with mesophilic aerobic and facultative anaerobic microorganisms (MAFAnM) did not depend on the dose and duration of consumption of the nanosilver drug by laying hens. The nanosilver drug in doses of 0.0, 0.2 and $0.4 \mathrm{mg}$ per hen per day did not affect the contamination of the egg shell surface with microorganisms of genera Citrobacter, Klebsiella, as well as Escherichia coli, Proteus mirabilis, Salmonella spp., Staphylococcus aureus and S. epidermidis. When administered orally, nanosilver in the dose of $0.2 \mathrm{mg}$ per hen per day did not change the number of symbiotic microorganisms of genera Bifidobacterium and Lactobacillus, while and the dose of $0.4 \mathrm{mg}$ per hen daily slightly reduced the number of microorganisms of genus Lactobacillus in the hens' manure. The obtained data can be used for further research to determine the effective dose and interval of application of nanosilver preparations to poultry for preventive and therapeutic measures, taking into account the preservation of the microbiome of the digestive system of hens.
\end{abstract}

Keywords: chemical composition of eggs; MAFAnM; lactobacilli; bifidobacteria; $\mathrm{AgNPs} / \mathrm{SPH}$.

Introduction

The ban on the use of antibiotics in industrial livestock, especially in poultry breeding, has prompted scientists to find new drugs having bactericidal, virucidal and fungicidal effects (Dhugosz et al., 2021). The rapid development of nanotechnology has led to the use of nanosilver drugs as antimicrobial agents in medical, textile, food, and veterinary practice (Motelica et al., 2020; Pulit-Prociak et al., 2020). A number of studies have shown that silver nanoparticles have a positive effect on animal productivity, stimulate immunogenesis (Anwar et al., 2019), may be effective in prevention and treatment of infectious diseases (Gopinath et al., 2016), and be efficient anticancer agents (Hamed et al., 2017; Salem et al., 2020). The study of the effectiveness of nanosilver preparations in industrial poultry farming is especially relevant, as the production, transportation, sale and storage of eggs are associated with the risk of contamination of the shell surface with opportunistic and pathogenic microflora that poses a threat to the consumers. According to Stępien-Pyśniak et al. (2010), the shell of chicken eggs during sale and storage is most often contaminated with two serotypes of bacteria of Salmonella genus: S. enteritidis and S. arizonae, as well as bacteria of Enterobacteriaceae family: Enterobacter spp., Klebsiella spp. and Citrobacter freundii. Qualitative analysis of the bacterial microflora of eggs also showed the presence of other Gramnegative bacteria, including Acinetobacter spp., Pseudomonas spp., Tatumella ptyseos, Providencia stuartii, Serratia liquefaciens, Flavimonas oryzihabitans, Vibrio metschnikovii, Leclercia adecarboxylata, Kluyvera spp., Rahnella aquatilis, Proteus mirabilis and Achromobacter spp. The use of nanosilver preparations to reduce microbial contamination of eggs is justified by the ability of AgNPs in 6.25-100.00 ppm concentrations to show antibacterial activity against a wide range of pathogens, including Staphylococcus aureus, Bacillus subtilis, Pseudomonas aeruginosa, Escherichia coli and Salmonella typhimurium (Hamed et al., 2017; Salem et al., 2020). In most cases, nanosilver is administered to poultry orally, further accumulating in various organs and tissues, which, along with reduction of the risk of infectious diseases of poultry and contamination of eggs for consumption with dangerous infectious agents, may damage the intestinal microbiome; today it is considered as an integral metabolic organ with numerous physiological functions (Zorraquín-Peñaet et al., 2020). The symbiotic ecosystem, consisting of more than 100 trillion bacteria, is essential for intestinal maturation, local angiogenesis, regulation of enterocyte gene expression, vitamin synthesis, support of homeostasis, innate and adaptive immunity.

Currently, there is a considerable amount of conflicting data on the effects of silver nanoparticles on the intestinal microbiome of different species of animals and humans, which are manifested by dysbacteriosis and other disorders (Lamas et al., 2020), and the use of nanosilver preparations in poultry farming still require studies determining the level of risk of microbial contamination of eggs for consumption and their chemical composition. The development of the new generation of nanosilver preparations, obtained and stabilized in aqueous solutions of synthetic and natural polymers (Rozenberg et al., 2008; Natsuki et al., 2015; Lee et al., 2019), and in the recent years in solutions of biocompatible and biodegradable polymer/inorganic hybrids (Zheltonozhskaya et al., 2021), makes 
it possible to reduce their doses and toxicity and increase the efficiency of their use due to production of very small silver nanoparticles in such carriers and increasing the duration of their action in a living organism. In this context, the objective of our research was the effect of different doses of nanosilver in carriers based on polymer/inorganic hybrids on the quality and safety of chicken eggs, as well as the symbiotic microorganisms of the intestines of laying hens.

\section{Materials and methods}

A grafted polymer/inorganic hybrid carrier (PIHC) based on silica nanoparticles and polyacrylamide chains was obtained by radical polymerization of acrylamide (AAm) from the surface of silica nanoparticles in accordance with the methodology developed in the study (Zheltonozhskaya et al., 2021). In this synthesis, we used samples of Aerosil A175 from "Orisil" (Ukraine), cerium (IV) ammonium nitrate (CAN) from "Aldrich" (USA) and AAm from "Merck" (Germany), as well as weight ratios $[\mathrm{CeIV}] /\left[\mathrm{SiO}_{2}\right]=0.2$ and $[\mathrm{CeIV}] /[\mathrm{AAm}]=7.72 \cdot 10^{-3}$, with the concentration of $\mathrm{CSiO}_{2}=1.35 \mathrm{~g} / \mathrm{L}$. The procedure was carried out at $23{ }^{\circ} \mathrm{C}$ in an inert (argon) atmosphere with stirring for 24 hours. The gelled product was diluted with deionized water, re-precipitated with acetone, then redissolved in water and freeze-dried. The main characteristics of PIHC were determined according to the study (Zheltonozhskaya et al., 2021) using static light scattering, elemental analysis, dynamic thermogravimetric analysis, viscometry, and transmission electron microscopy (TEM) (Table 1).

\section{Table 1}

Main parameters of polymer/inorganic hybrid carrier and the obtained silver preparation

\begin{tabular}{|c|c|c|c|c|c|}
\hline \multirow{2}{*}{ Sample } & \multicolumn{3}{|c|}{ Pure carrier } & \multicolumn{2}{|c|}{ Preparation } \\
\hline & $\mathrm{R}_{\mathrm{SiO} 2}{ }^{\mathrm{a}}, \mathrm{nm}$ & $\mathrm{M}_{\mathrm{vPAAm}}{ }^{\mathrm{b}}, \mathrm{kDa}$ & $\mathrm{N}^{\mathrm{c}} \mathrm{d}_{\mathrm{PIHC}}{ }^{\mathrm{d}}, \mathrm{nm}$ & $\mathrm{d}_{\mathrm{AgNPs}}{ }^{\mathrm{d}}, \mathrm{nm}$ & $\mathrm{d}_{\mathrm{AgNPSPH}}{ }^{\mathrm{e}}, \mathrm{nm}$ \\
\hline PIHC & 7.7 & 1513 & $20-45$ & $1.2-9.6$ & $\sim 31-47$ \\
\hline
\end{tabular}

Note: ${ }^{\text {a }}$ - average radius of silica nanoparticles determined by static light scattering; ${ }^{\mathrm{b}}$ viscosity-average molecular weight of PAAm grafted chains; ${ }^{\mathrm{c}}$ - average number of PAAm grafts per $\mathrm{SiO}_{2}$ particle; ${ }^{\mathrm{d}}$ - diameters of spherical particles of pure hybrid and silver found by TEM; ${ }^{\mathrm{e}}$ - effective diameters of hybrid particles with silver nanoparticles.

Then a preparation of nanosilver was obtained according to the previously developed method (Zheltonozhskaya et al., 2021) by in situ reduction of silver nitrate with sodium borohydride in an aqueous solution of a hybrid. For this synthesis, the concentrations of CPIHC $=1.0 \mathrm{~g} / \mathrm{L}$ and $\mathrm{CAgNO}_{3}=36.4 \mathrm{mg} / \mathrm{L}$ and an eight-fold molar excess of $\mathrm{NaBH}_{4}$ with respect to the silver salt were used. According to the standard protocol, the hybrid aqueous solution was mixed with $\mathrm{AgNO}_{3}$ at room temperature and stored for $30 \mathrm{~min}$ in a dark box; then a reducing agent was added. After three minutes, a yellow colour appeared, indicating the appearance of a dispersion of AgNPs in water. The formation of silver nanoparticles was also confirmed by the manifestation of a surface plasmon resonance band with $\lambda_{\max }=388 \mathrm{~nm}$ in the UV-Vis spectrum (Fig. 1).

Extinction spectra were recorded in the range of 200-1,000 nm using a Cary 50 Scan UV-Vis spectrometer manufactured by Varian (USA). The obtained nanosilver preparation was re-precipitated with ethanol, centrifuged at $6,000 \mathrm{rpm}$, and re-dissolved in deionized water to remove by-products of the reduction reaction. For subsequent biological experiments, this basic nanosilver preparation with CAgNPs $=24 \mathrm{mg} / \mathrm{L}$ was diluted to the required concentrations (CAgNPs $=1$ and $2 \mathrm{mg} / \mathrm{L}$ ).

Experiments on laying hens were conducted at the Faculty of Veterinary Medicine of the National University of Life and Environmental Sciences of Ukraine in compliance with the European Convention for the Protection of Vertebrate Animals used for Experimental and other Scientific Purposes adopted in 1986 and the Law of Ukraine "On protection of animals from abuse" of 21.02.2006 No. 3447-IV as amended on 04.08.2017.

For the experiment, we used 45 38-week-old Hy-Line W36 laying hens. Before the experiment, they were divided into three groups (15 individuals in each). The birds were given a solution of the nanosilver preparation in carriers based on polymer/inorganic hybrids in the concentrations of $0 \mathrm{mg} / \mathrm{L}$ (control), 1.0 and $2.0 \mathrm{mg} / \mathrm{L}$ of water (respectively, 0.0 ,
0.2 and $0.4 \mathrm{mg}$ per hen per day) three times with an interval of 10 days. During the experiment, hens of all groups were fed with commercial compound feed, balanced according to energy, nutrients and biologically active substances. Laying hens were fed according to the Management Guide W-36 commercial layers. The composition of the complete feed included the following components (\%): corn - 50.08, soybean meal 17.90, sunflower meal -9.60 , wheat -9.00 , limestone -1.14 , salt -0.23 , sorbent, mineral and vitamin complexes, and probiotic Proaktivo. One kg of Proaktivo contains: bacteria Bacillus licheniformis and B. subtilis, no less than $1 \cdot 10^{12} \mathrm{CFU}$, bacteria Enterococcus faecium, no less than 5 . $10^{10} \mathrm{CFU}$, fermentation products of Bacillus subtilis, Lactococcus lactis, Bacillus licheniformis $100 \mathrm{~g}$, xylanase 600,000 units, cellulase 20,000 units, protease 500 units, milk thistle meal $20 \mathrm{~g}$, acidity regulator $10 \mathrm{~g}$, betaine $10 \mathrm{~g}$, chitosan $0.1 \mathrm{~g}$, and yeast cell walls (mannan-oligosaccharides) $100 \mathrm{~g}$, natural aluminosilicates - up to $1 \mathrm{~kg}$.

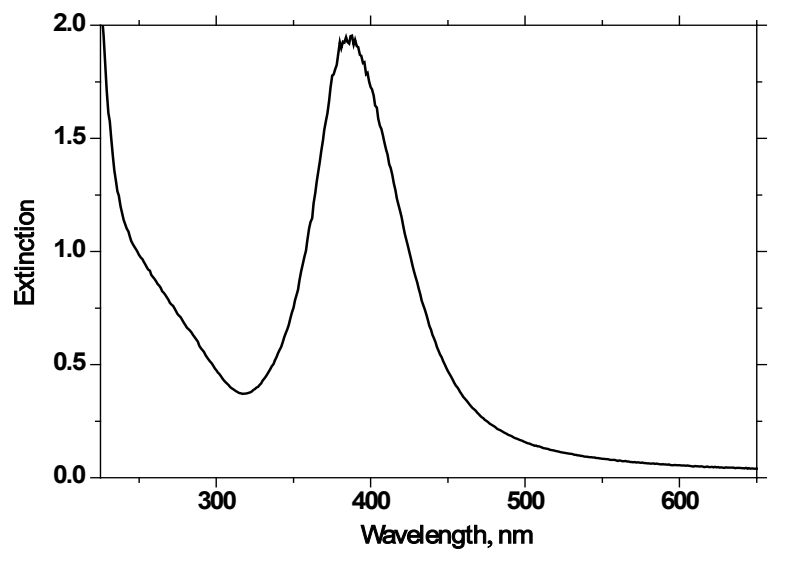

Fig. 1. Extinction spectrum of the $\mathrm{AgNO}_{3} / \mathrm{PIHC}$ mixture $13.3 \mathrm{~min}$ after the addition of the reducing agent: $\mathrm{CPIHC}=1 \mathrm{~g} / \mathrm{L}$; $\mathrm{CAgNO}_{3}=36.4 \mathrm{mg} / \mathrm{L} ; \mathrm{T}=20^{\circ} \mathrm{C}$

All groups of pullets had free access to water throughout the experiment. Drinking bowls with a graduated cylinder were used for watering the birds. During the experiment, the amounts of consumed water and the solution of the nanosilver preparation were monitored daily. The birds were kept in cages with egg collectors and group trough feeders, 5 individuals in each. In the room, hens of all experimental groups were provided with proper temperature-humidity and light regimes (16 hours a day (30 lux illumination), 8 hours of darkness).

The consumption of feed, water, egg productivity and the condition of hens in the groups were monitored throughout the experiment (30 days). On the 10th day after each feeding of the solution of the nanosilver preparation, in the morning before feeding, we collected 5 eggs and 5 samples of manure from each group of hens in sterile bags.

The contents of water, dry matter, crude ash, crude protein, crude fat, calcium and phosphorus were determined in the eggs. The mass fraction of moisture was determined by successive weighing and drying of the egg samples in an oven. Dry matter in egg samples was calculated on the basis of data of mass moisture content. The mass nitrogen content in eggs was determined using the Kjeldahl method, mineralization of samples was performed using a digester for wet mineralization DK 6 (Velp Scientifica, Italy), and the distillation of ammonia was carried out on a semi-automatic apparatus for steam distillation according to Kjeldahl UDK 129 (Velp Scientifica, Italy). The mass protein content was calculated after determining nitrogen in the egg samples. The mass ash content in eggs was determined by burning samples in a muffle furnace Nabertherm L15 (Germany). The mass fat content was determined by degreasing the egg samples with diethyl ether using the Soxhlet method with an automatic extraction device SER 148 (Velp Scientifica, Italy). The content of calcium and phosphorus was determined in crude ash after mineralization of eggs by colorimetric method. To determine the number of mesophilic aerobic and mesophilic anaerobic microorganisms (MAFAnM), bacteria of the genera Citrobacter, Klebsiella, Salmonella spp., as well as E. coli, $P$. mirabilis, $S$. aureus and $S$. epidermidis, we used eggshell surface rinses. 
The number of MAFAnM was determined in the yolks of freshly laid chicken eggs. The number of bacteria of genera Bifidobacterium and Lactobacillus was determined in the manure of hens. For this purpose, we prepared subsequent nine-fold dilutions in sterile saline. Analyses of the microflora in the manure, on the shells and in egg yolks were performed simultaneously. Bacteriological studies used medium and diagnostic tests manufactured by HiMedia (India).

Platecountagar M091 medium was used to determine the amount of MAFAnM on the surface of the shells and in the egg yolks. MacConkey Broth M007 and Endo Agar M029 media were used to isolate and calculate bacteria of the genera Citrobacter, Klebsiella; Bifidobacterium Agar M 1396 for Bifidobacterium; Lactobacillus MRS Agar M641 for Lactobacillus. To isolate pathogenic and non-pathogenic staphylococci, we used Baird Parker Agar M043; for P. mirabilis - Xylose Lysine Deoxycholate Agar M031; for Salmonella - Bismuth Sulphite Agar M027 and Xylose Lysine Deoxycholate Agar M031. The number of microorganisms was expressed in colony-forming units (CFU), the results were expressed in $\mathrm{lg} \mathrm{CFU} / \mathrm{cm}^{2}$ of egg shell surface and $\mathrm{lg} \mathrm{CFU} / \mathrm{g}$ of yolk or manure. Genus and species identification of isolated microorganisms were performed according to current methods.

Statistical processing of the obtained results was performed using the ANOVA software. The data in the tables are presented in the form of $\mathrm{x} \pm$ $\mathrm{SD}$ (mean \pm standard deviation). The difference between the groups was considered significant using the Tukey test at $\mathrm{P}<0.05$ (taking into account the Bonferroni correction)

\section{Results}

Feeding laying hens with the solution of nanosilver in carriers based on polymer/inorganic hybrids in the doses of 0.2 and $0.4 \mathrm{mg}$ per hen per day did not significantly affect water and compound feed consumption compared to the control during the entire period of the experiment (Table 2). Also, there was no significant difference between egg production by hens that consumed solutions of the nanosilver preparations in carriers based on polymer/inorganic hybrids in the doses of $0.0,0.2$ and $0.4 \mathrm{mg}$ per hen per day.

\section{Table 2}

Consumption of feed, water, and egg productivity of laying hens consuming the preparations of nanosilver in carriers based on polymer/inorganic hybrids $(\mathrm{x} \pm \mathrm{SD}, \mathrm{n}=15)$

\begin{tabular}{lcc}
\hline & Indicator & \multicolumn{2}{c}{ The dose of AgNPs/SPH, $\mathrm{mg} /$ hen } & 0.2 \\
\cline { 2 - 3 } & Single administration of AgNPs/SPH & 0.4 \\
\hline Consumption of compound feed, ghen per day & $97.0 \pm 0.0$ & $97.0 \pm 0.0$ \\
Water consumption, mL/hen per day & $205.2 \pm 2.0$ & $202.8 \pm 2.0$ \\
Average daily egg production, eggs & $14.5 \pm 0.2$ & $14.8 \pm 0.1$ \\
\hline & Two administrations of AgNPs/SPH & $97.0 \pm 0.0$ \\
Consumption of compound feed, g/hen per day & $97.0 \pm 0.0$ & $203.6 \pm 1.9$ \\
Water consumption, mL/hen per day & $202.1 \pm 1.9$ & $14.6 \pm 0.2$ \\
Average daily egg production, eggs & $14.6 \pm 0.2$ & $202.6 \pm 1.8$ \\
\hline & Three administrations of AgNPs/SPH & $14.8 \pm 0.1$ \\
\hline Consumption of compound feed, g/hen per day & $97.0 \pm 0.0$ & $201.8 \pm 2.1$ \\
Water consumption, mL/hen per day & $202.9 \pm 2.3$ & $14.9 \pm 0.1$ \\
Average daily egg production, eggs & $14.7 \pm 0.2$ & $97.0 \pm 0.0$ \\
\hline
\end{tabular}

Note: no differences were found between the consumption of hen compound feed by hen, as its daily norm was consumed completely without residues.

Table 3

Chemical composition of chicken eggs produced by hens consuming nanosilver preparations in carriers based on polymer/inorganic hybrids $(\%, \mathrm{x} \pm \mathrm{SD}, \mathrm{n}=5)$

\begin{tabular}{|c|c|c|c|}
\hline \multirow{2}{*}{ Indicator } & \multicolumn{3}{|c|}{ The dose of AgNPs/SPH, mg/hen } \\
\hline & 0.0 & 0.2 & 0.4 \\
\hline \multicolumn{4}{|c|}{ Single administration of AgNPs/SPH } \\
\hline Moisture & $76.12 \pm 0.12$ & $76.07 \pm 0.15$ & $74.65 \pm 0.62$ \\
\hline Dry matter & $23.88 \pm 0.11$ & $23.93 \pm 0.15$ & $23.35 \pm 0.62$ \\
\hline Crude protein & $13.61 \pm 0.31$ & $13.78 \pm 0.24$ & $12.87 \pm 0.48$ \\
\hline Crude fat & $9.52 \pm 0.29$ & $11.74 \pm 0.92$ & $9.58 \pm 0.58$ \\
\hline Crude ash & $0.99 \pm 0.10$ & $0.99 \pm 0.03$ & $1.06 \pm 0.05$ \\
\hline $\mathrm{Ca}$ & $0.055 \pm 0.004$ & $0.061 \pm 0.001$ & $0.059 \pm 0.001$ \\
\hline $\mathrm{P}$ & $0.141 \pm 0.007$ & $0.190 \pm 0.012$ & $0.170 \pm 0.010$ \\
\hline \multicolumn{4}{|c|}{ Two administrations of AgNPs/SPH } \\
\hline Moisture & $75.68 \pm 0.39$ & $75.42 \pm 1.96$ & $75.39 \pm 0.57$ \\
\hline Dry matter & $24.32 \pm 0.39$ & $24.58 \pm 1.96$ & $24.61 \pm 0.57$ \\
\hline Crude protein & $13.90 \pm 0.41$ & $13.83 \pm 0.17$ & $13.04 \pm 0.31$ \\
\hline Crude fat & $9.55 \pm 0.48$ & $10.04 \pm 0.55$ & $9.80 \pm 0.22$ \\
\hline Crude ash & $1.03 \pm 0.04$ & $1.05 \pm 0.04$ & $0.93 \pm 0.05$ \\
\hline $\mathrm{Ca}$ & $0.051 \pm 0.006$ & $0.054 \pm 0.006$ & $0.057 \pm 0.004$ \\
\hline $\mathrm{P}$ & $0.166 \pm 0.022$ & $0.160 \pm 0.022$ & $0.170 \pm 0.014$ \\
\hline \multicolumn{4}{|c|}{ Three administrations of $\mathrm{AgNPs} / \mathrm{SPH}$} \\
\hline Moisture & $75.56 \pm 0.73$ & $75.93 \pm 1.10$ & $75.44 \pm 0.75$ \\
\hline Dry matter & $24.44 \pm 0.73$ & $24.07 \pm 1.10$ & $24.56 \pm 0.75$ \\
\hline Crude protein & $14.49 \pm 0.53$ & $13.99 \pm 0.96$ & $14.39 \pm 0.31$ \\
\hline Crude fat & $10.16 \pm 0.76$ & $10.21 \pm 0.41$ & $10.61 \pm 0.55$ \\
\hline Crude ash & $1.03 \pm 0.03$ & $1.11 \pm 0.08$ & $1.06 \pm 0.06$ \\
\hline $\mathrm{Ca}$ & $0.058 \pm 0.003$ & $0.052 \pm 0.002$ & $0.060 \pm 0.001$ \\
\hline $\mathrm{P}$ & $0.181 \pm 0.013$ & $0.184 \pm 0.019$ & $0.203 \pm 0.004$ \\
\hline
\end{tabular}

Analysis of the chemical composition of eggs obtained from hens of the experimental groups showed no effect of nanosilver on moisture, dry matter, crude protein, crude fat, crude ash, as well as calcium and phosphorus compared with the control (Table 3). Throughout the experiment, during the use of nanosilver in polymer-based/inorganic hybrid carriers at doses of $0.0,0.2$ and $0.4 \mathrm{mg}$ per hen per day, we found no colonies of microorganisms of the genus Citrobacter, Klebsiella, also E. coli and $P$. mirabilis, which belong to the opportunistic microflora, on the shell surface of freshly laid eggs. Furthermore, no colonies of pathogenic Salmonella spp., S. aureus and S. epidermidis were found on the surfaces of eggshells of eggs from chicken of the experimental groups throughout the experiment.

The number of MAFAnM on the surface of the shell and in the yolks of eggs at single, two and three consumptions of solution of nanosilver in carriers based on polymer/inorganic hybrids by the hens significantly did not depend on its dose and expiration date (Table 4).

Table 4

Contamination of MAFAnM chicken eggs with the use of nanosilver in carriers based on polymer/inorganic hybrids $(\mathrm{x} \pm \mathrm{SD}, \mathrm{n}=5)$

\begin{tabular}{lccc}
\hline \multirow{2}{*}{$\begin{array}{c}\text { The frequency of application } \\
\text { of AgNPs/SPH to hens }\end{array}$} & \multicolumn{3}{c}{ The dose of AgNPs/SPH, $\mathrm{mg} / \mathrm{hen}$} \\
\cline { 2 - 4 } & \multicolumn{4}{c}{ Egg shell surface, $\lg \mathrm{CFU} / \mathrm{cm}^{2}$} \\
\hline \multicolumn{4}{c}{0.2} \\
\hline Single & $3.2 \pm 0.1$ & $3.3 \pm 0.1$ & $3.4 \pm 0.1$ \\
Two & $3.0 \pm 0.2$ & $3.1 \pm 0.1$ & $3.0 \pm 0.1$ \\
Three & $3.1 \pm 0.1$ & $3.1 \pm 0.1$ & $2.9 \pm 0.03$ \\
\hline \multicolumn{4}{c}{ Yolk, lg CFU/g } \\
\hline Single & $2.6 \pm 0.2$ & $2.8 \pm 0.05$ & $2.8 \pm 0.1$ \\
Two & $2.4 \pm 0.1$ & $2.7 \pm 0.1$ & $2.6 \pm 0.1$ \\
Three & $2.5 \pm 0.2$ & $2.5 \pm 0.1$ & $2.4 \pm 0.2$ \\
\hline
\end{tabular}

Analysis of the amount of symbiotic microflora in chicken manure showed that single, two and three admissions of nanosilver solution in carriers based on polymer/inorganic hybrids in the doses of $0.0,0.2$ and $0.4 \mathrm{mg}$ per hen a day did not affect the number of colonies of microorga- 
nisms of genus Bifidobacterium. The number of bacteria of genus Lactobacillus in the manure of hens of the experimental groups did not change after application of the drug nanosilver in the dose of $0.2 \mathrm{mg}$, nonetheless the dose of $0.4 \mathrm{mg}$ per hen per day slightly decreased their number $(\mathrm{P}<$ 0.05 ) after two and three applications compared with control (Table 5).

\section{Table 5}

The number of bacteria of Lactobacillus and Bifidobacterium genera in the manure of laying hens that consumed the nanosilver preparation in carriers based on polymer/inorganic hybrids ( $\lg \mathrm{CFU} / \mathrm{g}, \mathrm{x} \pm \mathrm{SD}, \mathrm{n}=5$ )

\begin{tabular}{|c|c|c|c|}
\hline \multirow{2}{*}{ Genus of bacteria } & \multicolumn{3}{|c|}{ The dose of AgNPs/SPH, mg/hen } \\
\hline & 0.0 & 0.2 & 0.4 \\
\hline \multicolumn{4}{|c|}{ Single administration of AgNPs/SPH } \\
\hline Bifidobacterium & $7.82 \pm 0.01^{\mathrm{a}}$ & $7.89 \pm 0.03^{\mathrm{a}}$ & $7.82 \pm 0.02^{\mathrm{a}}$ \\
\hline Lactobacillus & $7.86 \pm 0.05^{\mathrm{a}}$ & $7.77 \pm 0.01^{\mathrm{a}}$ & $7.72 \pm 0.02^{\mathrm{a}}$ \\
\hline \multicolumn{4}{|c|}{ Two administrations of AgNPs/SPH } \\
\hline Bifidobacterium & $7.80 \pm 0.01^{\mathrm{a}}$ & $7.88 \pm 0.02^{\mathrm{a}}$ & $7.80 \pm 0.03^{\mathrm{a}}$ \\
\hline Lactobacillus & $7.81 \pm 0.01^{\mathrm{a}}$ & $7.76 \pm 0.02^{\mathrm{a}}$ & $7.69 \pm 0.01^{\mathrm{b}}$ \\
\hline \multicolumn{4}{|c|}{ Three administrations of AgNPs/SPH } \\
\hline Bifidobacterium & $7.91 \pm 0.17^{\mathrm{a}}$ & $7.78 \pm 0.02^{\mathrm{a}}$ & $7.74 \pm 0.03^{\mathrm{a}}$ \\
\hline Lactobacillus & $7.81 \pm 0.01^{\mathrm{a}}$ & $7.65 \pm 0.07^{\mathrm{ab}}$ & $7.50 \pm 0.03^{b}$ \\
\hline
\end{tabular}

Note: different uppercase letters ${ }^{\mathrm{a}} ;{ }^{\mathrm{b}}$ indicate values that probably differed in one row of the table $(\mathrm{P}<0.05)$ by comparison using Tukey test with Bonferroni correction.

\section{Discussion}

As can be seen from our research results, the preparation of nanosilver in carriers based on polymer/inorganic hybrids did not affect the average daily consumption of feed, water and egg production of hens. That is consistent with data obtained on broiler chickens by Vadalasetty et al. (2018) for $8.26 \mathrm{mg} /$ day doses of AgNPs and Kulak et al. (2018) for 2.87 and $12.25 \mathrm{mg}$ per bird doses. In addition, in another study, administration of $15 \mathrm{~nm}$ nanosilver in the concentration of $50 \mathrm{mg} / \mathrm{L}$ of water increased feed intake and body weight of domestic chickens (Kumar \& Bhattacharya, 2019). In contrast to these studies, Farzinpour et al. (2013) found a negative effect of nanosilver in the doses of $0,4,8$ and $12 \mathrm{ppm}$ in feed, which was manifested by a decrease in egg yolk mass and egg production of Japanese quails.

According to our studies, the nanosilver preparation in carriers based on polymer/inorganic hybrids in the doses of 0.2 and $0.4 \mathrm{mg}$ per hen per day did not affect the chemical composition of chicken eggs, which is consistent with the level of feed and water consumption by poultry throughout the experiment. Our results are difficult to compare with other data due to their lack in the available literature.

One of the parameters of egg safety is the level of contamination of their shell with dangerous microflora (Stepien-Pyśniak, 2010). The microflora of the surface of the egg shell in birds is largely determined by the species composition and its ratio in the intestinal contents, especially the colon (Maki et al., 2020). In contrast to the effect of antibiotics on the intestinal microflora, the mechanism of action of nanosilver drugs on the microbiome of different parts of the intestine of hens has not been studied. In birds, the peculiarity of egg production is the presence of contact of the mucous membrane of the cloaca with the surface of the egg shell, which provides a vertical path of transmission of microflora. We found no contamination of the surface of the shell of freshly laid eggs with opportunistic and pathogenic microorganisms of genera Citrobacter, Klebsiella, as well as E. coli, P. mirabilis, Salmonella spp., S. aureus and S. epidermidis both at different doses of nanosilver and in hens of the control group. This is due to the bactericidal properties of the cuticle of the egg shell (Ohshima et al., 2015; Chen et al., 2019).

The number of mesophilic aerobic and mesophilic anaerobic microorganisms on the shell surface of eggs from hens that consumed nanosilver drug in carriers based on polymer/inorganic hybrids in our experiment did not differ between groups of experimental hens. That suggests that the main microorganisms belonging to MAFAnM on the surface of the eggshell of hens in our case were bacteria that formed the basis of the Proactivo probiotic used in feed, as well as bacteria of genera Bifidobacterium and Lactobacillus, the development of which in the intestines of hens was likely promoted by this probiotic (Elshaghabee et al., 2017). That is con- sistent with the number of bacteria of genera Bifidobacterium and Lactobacillus in the manure of hens that received the preparation of nanosilver in carriers based on polymer/inorganic hybrids with water in doses of 0.0 , 0.2 and $0.4 \mathrm{mg}$ per hen a day. Moreover, in our studies we did not note the effect of this drug on the number of bacteria of genus Bifidobacterium, while the number of bacteria of genus Lactobacillus in hen manure decreased slightly at the dose of $0.4 \mathrm{mg}$ per hen per day with increasing frequency of drug administration. Another experiment revealed no effect of AgNPs on the intestinal microflora in birds against the background of weight gain with a decrease in the relative weight of the bursa and spleen, accompanied by a decrease in plasma IgG and IgM (Vadalasetty et al., 2018).

The effect of nanosilver preparations on the intestinal microbiome of hens has been studied insufficiently, while a significant number of studies have been performed on laboratory animals showing that oral nanoparticles of silver (10, 75 and $110 \mathrm{~nm}$ ) and nanosilver acetate in SpragueDawley rats in the doses of AgNPs equaling 9, 18 and $36 \mathrm{mg} / \mathrm{kg}$ body weight per day caused shifts in the intestinal microbiota towards increase in the proportion of Gram-negative bacteria and decrease in the populations of Firmicutes phyla and genus Lactobacillus (Williams et al., 2015). By contrast, the data obtained after oral repeated administration of AgNPs to mice $(20$ and $110 \mathrm{~nm}$ ) in the dose of $10 \mathrm{mg} / \mathrm{kg}$ body weight per day indicated no changes in the composition, structure and diversity of the intestinal microbiome. Wilding et al. (2016) conclude that by contrast to the effects of broad-spectrum antibiotics, repeated dosing of AgNPs does not affect the intestinal microbiome of mice and can be considered as an alternative to broad-spectrum antibiotics. Conversely, the study by van den Brule et al. (2015) points out that AgNPs can cause changes in the microbial composition of the intestine of mice, characteristic of obesity and inflammatory diseases, as well as the appointment of antibiotics. Disorders of the intestinal microbiome under the influence of AgNPs in mice in the study of Chen et al. (2017) was associated with disruption of microvilli structure and dense connections in the intestinal epithelium, as well as regulation of proinflammatory cytokine synthesis. Gene analysis by ${ }^{16} \mathrm{~S}$ rRNA sequencing showed that oral administration of AgNPs to mice caused changes in the number and ratio of intra- and interphilous bacteria and firmicutes, decreased the ratio of Firmicutes/Bacteroidetes, increased the number of rare bacteria and reduced the number of probiotic bacteria of genus Lactobacillus.

A study by Javurek et al. (2017) confirmed that the effect of nanosilver nanoparticles on the intestinal microbiome depends on their shape and causes histopathological changes in the gastrointestinal tract and brain. In male Sprague-Dawley rats, the two-week consumption of cubic AgNPs reduced the numbers of Clostridium spp., Bacteroides uniformis, Christensenellaceae, and Coprococcus eutactus, whereas the spherical shape of nanoparticles of nanosilver reduced the number of Oscillospira spp., Dehalobacterium spp., Peptococcaeceae, Corynebacterium spp., and Aggregatibacter pneumotropica.

Although the antibacterial properties of nanosilver nanoparticles have been demonstrated throughout the spectrum of bacterial pathogens, the effect of AgNPs on beneficial bacteria is studied poorly. Comparison of the antibacterial activity of AgNPs against two beneficial lactobacilli (Lactobacillus delbrueckii subsp. Bulgaricus and Lactobacillus casei) and two common opportunistic pathogens (Escherichia coli and Staphylococcus aureus) showed that lactobacilli are more susceptible to AgP, which is coherent with our data (Table 5). The acidic environment formed by lactobacilli enhances the bactericidal action of AgNPs by increasing their dissolution and the formation of hydroxyl radicals $(-\mathrm{OH})$. In addition, the increase in the concentration of nanosilver $\left(\mathrm{Ag}^{+}\right)$and $-\mathrm{OH}$ ions depletes the pool of glutathione inside the cell of the microorganism, which is associated with an increase in the content of intracellular reactive oxygen species. High levels of reactive oxygen species in the environment can cause DNA damage and lead to further cell death (Tian et al., 2018). These results also indicate that oral administration of AgNPs alters the mucosalassociated microbiota and modulates the intestinal immune response and overall intestinal homeostasis in animals. Nanosilver is an effective bactericidal agent against Gram-negative and Gram-positive strains, and its activity depends on the thickness of the peptidoglycan layer of the bacterial wall. Nanosilver ions can bind to the negatively charged surface of bac- 
teria and disrupt its integrity. AgNPs and ions are also able to enter bacterial cells and interfere with the functioning of the respiratory chain and the absorption of phosphates. Disorders of DNA replication or protein modification, as well as strong interactions with cytoplasmic and membrane proteins containing thiol, may also enhance the bactericidal effects of AgNPs (Jung et al., 2008; Völker et al., 2013).

Consumption of nanosilver in carriers based on polymer/inorganic hybrids may be considered a way to reduce the accumulation of residues of antibiotics and other antibacterial drugs in food, including eggs and poultry meat (Bayer et al., 2017), which may to some extent solve not only medical but also environmental problems.

\section{Conclusions}

One-, two- and three administrations of nanosilver based on polymer/ inorganic hybrids to hens in doses of 0.2 and $0.4 \mathrm{mg}$ per hen per day together with drinking water did not affect water consumption, feed, egg productivity of hens and chemical composition of eggs which characterizes their quality. The nanosilver preparation in carriers based on polymer/inorganic hybrids did not affect the contamination of the surface of the shell and yolks of chicken eggs with MAFnM. The intake of nanosilver in carriers based on polymer/inorganic hybrids by laying hens in the doses of 0.0, 0.2 and $0.4 \mathrm{mg}$ per hen per day caused no accumulation of opportunistic and pathogenic microorganisms of genera Citrobacter, Klebsiella, and E. coli, P. mirabilis, Salmonella spp., S. aureus and S. epidermidis on the surface of the shell. In the dose of $0.4 \mathrm{mg}$ per hen per day, the nanosilver preparation in polymer/inorganic hybrid carriers did not affect the number of microorganisms of genus Bifidobacterium and caused no significant reduction of the number of bacteria of genus Lactobacillus in the manure of hens. The results of the research indicate the safety of the nanosilver drug in carriers based on polymer/inorganic hybrids for laying hens and can be used to determine the effective regime of using nanosilver drugs in poultry farming.

\section{References}

Anwar, M., Awais, M., Akhtar, M., Navid, M., \& Muhammad, F. (2019). Nutritional and immunological effects of nano-particles in commercial poultry birds. World's Poultry Science Journal, 75(2), 261-272.

Bayer, E. V., Novozhitskaya, Y. N., Shevchenko, L. V., \& Mykhalska, V. M. (2017). Monitoring of residues of veterinary preparations in food products. Ukrainian Journal of Ecology, 7(3), 251-257.

Chen, H., Zhao, R., Wang, B., Cai, C., Zheng, L., Wang, H., Wang, M., Ouyang, H., Zhou, X., Chai, Z., Zhao, Y., \& Feng, W. (2017). The effects of orally administered $\mathrm{Ag}, \mathrm{TiO}_{2}$ and $\mathrm{SiO}_{2}$ nanoparticles on gut microbiota composition and colitis induction in mice. NanoImpact, 8, 80-88.

Chen, X., Li, X., He, Z., Hou, Z., Xu, G., Yang, N., \& Zheng, J. (2019). Comparative study of eggshell antibacterial effectivity in precocial and altricial birds using Escherichia coli. PLoS One, 14(7), e0220054.

Dhugosz, O., Sochocka, M., Ochnik, M., \& Banach, M. (2021). Metal and bimetallic nanoparticles: Flow synthesis, bioactivity and toxicity. Journal of Colloid and Interface Science, 586, 807-818.

Elshaghabee, F., Rokana, N., Gulhane, R. D., Sharma, C., \& Panwar, H. (2017) Bacillus as potential probiotics: Status, concerns, and future perspectives. Frontiers in Microbiology, 8, 1490.

Farzinpour, A., \& Karashi, N. (2013). The effects of nanosilver on egg quality traits in laying Japanese quail. Applied Nanoscience, 3, 95-99.

Gopinath, P., Ranjani, A., Dhanasekaran, D., Thajuddin, N., Archunan, G., Akbarsha, M. A., Gulyás, B., \& Padmanabhan, P. (2016). Multi-functional nano silver: A novel disruptive and theranostic agent for pathogenic organisms in realtime. Scientific Reports, 6, 34058.

Hamed, S., Emara, M., Shawky, R. M., El-Domany, R. A., \& Youssef, T. (2017). Silver nanoparticles: Antimicrobial activity, cytotoxicity, and synergism with Nacetyl cysteine. Journal of Basic Microbiology, 57(8), 659-668.

Javurek, A. B., Suresh, D., Spollen, W. G., Hart, M. L., Hansen, S. A., Ellersieck, M. R., Bivens, N. J., Givan, S. A., Upendran, A., Kannan, R., \& Rosenfeld,
C. S. (2017). Gut dysbiosis and neurobehavioral alterations in rats exposed to silver nanoparticles. Scientific Reports, 7(1), 2822.

Jung, W. K., Koo, H. C., Kim, K. W., Shin, S., Kim, S. H., \& Park, Y. H. (2008). Antibacterial activity and mechanism of action of the silver ion in Staphylococcus aureus and Escherichia coli. Applied and Environmental Microbiology, 74, 2171-2178.

Kulak, E., Ognik, K., Stępniowska, A., \& Sembratowicz, I. (2018). The effect of administration of silver nanoparticles on silver accumulation in tissues and the immune and antioxidant status of chickens. Journal of Animal and Feed Sciences, 27(1), 44-54.

Lamas, B., Breyner, N. M., \& Houdeau, E. (2020). Impacts of foodborne inorganic nanoparticles on the gut microbiota-immune axis: Potential consequences for host health. Particle and Fibre Toxicology, 17(1), 19.

Lee, S. H., \& Jun, B.-H. (2019). Silver nanoparticles: Synthesis and application for nanomedicine. International Joumal of Molecular Sciences, 20, 865.

Maki, J. J., Bobeck, E. A., Sylte, M. J., \& Looft, T. (2020). Eggshell and environmental bacteria contribute to the intestinal microbiota of growing chickens. Journal of Animal Science and Biotechnology, 11, 60.

Motelica, L., Ficai, D., Ficai, A., Truşcă, R. D., Ilie, C. I., Oprea, O. C., \& Andronescu, E. (2020). Innovative antimicrobial chitosan/ZnO/Ag NPs/citronella essential oil nanocomposite-potential coating for grapes. Foods, 9(12), 1801.

Natsuki, J., Natsuki, T., \& Hashimoto, Y. A. (2015). Review of silver nanoparticles: Synthesis methods, properties and applications. International Journal of Materials Science and Applications, 4, 325-332.

Ohshima, Y., Takada, D., Namai, S., Sawai, J., Kikuchi, M., \& Hotta, M. (2015). Antimicrobial characteristics of heated eggshell powder. Biocontrol Science, 20(4), 239-246.

Pulit-Prociak, J., Staron, A., Staroń, P., Chmielowiec-Korzeniowska, A., Drabik, A., Tymczyna, L., \& Banach, M. (2020). Preparation and of PVA-based compositions with embedded silver, copper and zinc oxide nanoparticles and assessment of their antibacterial properties. Journal of Nanobiotechnology, 18(1), 148.

Rozenberg, B. A., \& Tenne, R. (2008). Polymer-assisted fabrication of nanoparticles and nanocomposites. Progress in Polymer Science, 33, 40-112.

Salem, S. S., El-Belely, E. F., Niedbała, G., Alnoman, M. M., Hassan, S. E., Eid, A. M., Shaheen, T. I., Elkelish, A., \& Fouda, A. (2020). Bactericidal and in-vitro cytotoxic efficacy of silver nanoparticles (Ag-NPs) fabricated by endophytic Actinomycetes and their use as coating for the textile fabrics. Nanomaterials, 10(10), 2082.

Stepień-Pyśniak, D. (2010). Occurrence of gram-negative bacteria in hens' eggs depending on their source and storage conditions. Polish Journal of Veterinary Sciences, 13(3), 507-513.

Tian, X., Jiang, X., Welch, C., Croley, T. R., Wong, T.-Y., Chen, C., Fan, S., Chong, Y., Li, R., Ge, C., Chen, C., \& Yin, J.-J. (2018). Bactericidal effects of silver nanoparticles on lactobacilli and the underlying mechanism. ACS Applied Materials and Interfaces, 10(10), 8443-8450.

Vadalasetty, K. P., Lauridsen, C., Engberg, R. M., Vadalasetty, R., Kutwin, M., Chwalibog, A., \& Sawosz, E. (2018). Influence of silver nanoparticles on growth and health of broiler chickens after infection with Campylobacter jejuni. BMC Veterinary Research, 14(1), 1.

van den Brule, S., Ambroise, J., Lecloux, H., Levard, C., Soulas, R., de Temmerman, P.-J., Palmai-Pallag, M., Marbaix, E., \& Lison, D. (2015). Dietary silver nanoparticles can disturb the gut microbiota in mice. Particle and Fibre Toxicology, $13,38$.

Völker, C., Oetken, M., \& Oehlmann, J. (2013). The biological effects and possible modes of action of nanosilver. Reviews of Environmental Contamination and Toxicology, 223, 81-106.

Wilding, L. A., Bassis, C. M., Walacavage, K., Hashway, S., Leroueil, P. R., Morishita, M., Maynard, A. D., Philbert, M. A., \& Bergin, I. L. (2016). Repeated dose (28-day) administration of silver nanoparticles of varied size and coating does not significantly alter the indigenous murine gut microbiome. Nanotoxicology, 10(5), 513-520.

Williams, K., Milner, J., Boudreau, M. D., Gokulan, K., Cerniglia, C. E., \& Khare, S. (2015). Effects of subchronic exposure of silver nanoparticles on intestinal microbiota and gut-associated immune responses in the ileum of Sprague-Dawley rats. Nanotoxicology, 9(3), 279-289.

Zheltonozhskaya, T. B., Permyakova, N. M., Kravchenko, O. O., Maksin, V. I., Nessin, S. D., Klepko, V. V., \& Klymchuk, D. O. (2021). Polymer/inorganic hybrids containing silver nanoparticles and their activity in the disinfection of fish aquariums/ponds. Polymer-Plastics Technology and Materials, 60(4), 369-391.

Zorraquín-Peña, I., Cueva, C., Bartolomé, B., \& Moreno-Arribas, M. V. (2020). Silver nanoparticles against foodborne bacteria. Effects at intestinal level and health limitations. Microorganisms, 8(1), 132. 